\title{
E-Government Success Factors: Views of Saudi Professionals
}

Fahad Bin Muhaya, Saad Haj Bakry and Suhail M AlAlmaee

King Saud University, Riyadh, Saudi Arabia

\begin{abstract}
E-Government success is associated with various factors. This paper is concerned with exploring such factors and investigating, through a survey, how e-government professionals view them, as this would help finding ways for the future promotion of e-government success. The work identifies "35" success factors associated with seven levels including: "the international level, the national level, the sector level, the organization level, the requirements level, the services level, and the user level". The survey asks e-government professionals to assess each factor from the viewpoints of importance and current state or impact. This assessment has six grades starting from "no" importance or impact and moving up to: "low, below average, average, above average, and high". "88" Saudi e-government professionals participated in the survey. The results obtained show that the importance of most success factors considered has been above average or close to "high", except for few which were slightly less. The results also emphasized the gap between importance and current state or impact for each factor. This gap ranged from " $40 \%$ " to over " $80 \%$ ". The work provides useful knowledge for the future development of e-government. It is an example of a knowledge sharing exercise that should become a normal practice for the purpose of achieving development based on collective wisdom. This practice can be expanded to include users for whom the services are provided.
\end{abstract}

Keywords: e-Government: importance; Impact; Knowledge sharing; Future development

\section{Introduction}

This section introduces the work presented in this paper in three steps. It starts by emphasizing the importance of e-government. This is followed by viewing the support e-government development is receiving at various levels. The problem considered by the paper and its benefits are then presented.

\section{Importance of e-government}

It is widely accepted that using information and communication technology (ICT) to provide various government and business services provides: faster, cheaper, better, different, and more secure (FCBDS) services [1]. This provides advanced efficiency and enhanced effectiveness not only to those concerned, but also to society as a whole [2]. In this respect, government services have special importance, as every government is the sole organization in its own country, where it provides services to all businesses and individuals that no other organization can do.

Figure 1 provides an illustrative view of the various dimensions of

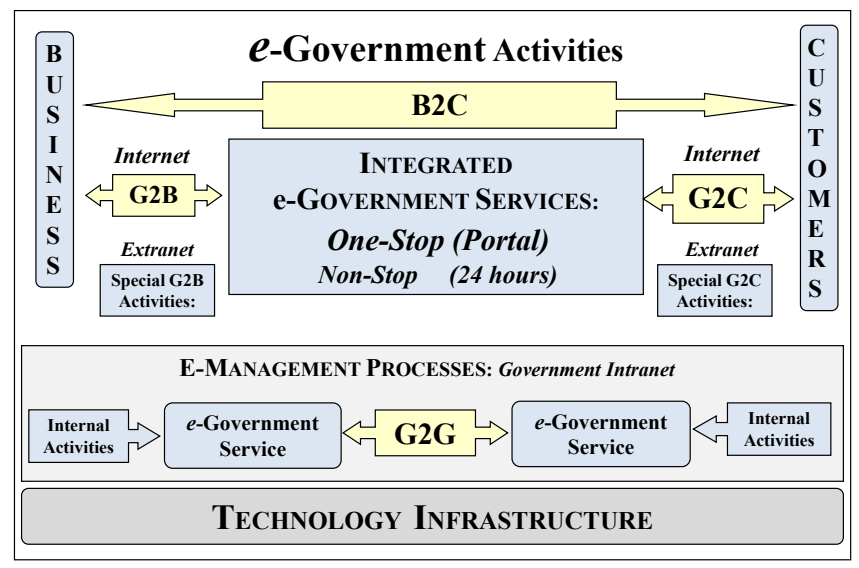

Figure 1: A general view of e-government. e-government services [3]. It shows that these services can be made available 24 hours for citizens (G-C) and for businesses (G-B); and that they support interaction among government departments $(G-G)$, in addition to directly or indirectly enhancing interaction among citizens and businesses (C-B).

E-government should enable anyone visiting a city website to communicate and interact with city employees via the Internet with graphical user interfaces (GUI), instant-messaging (IM), audio/video presentations, and in any way more sophisticated than a simple email letter to the address provided at the site" and "the use of technology to enhance the access to and delivery of government services to benefit citizens, business partners and employees". The focus should be on:

- The use of information and communication technologies, and particularly the Internet, as a tool to achieve better government.

- The use of information and communication technologies in all facets of the operations of a government organization.

- The continuous optimization of service delivery, constituency participation and governance by transforming internal and external relationships through technology, the Internet and new media.

Whilst e-government has traditionally been understood as being centered on the operations of government, e-governance is understood to extend the scope by including citizen engagement and participation in governance. As such, following in line with the OECD definition of

*Corresponding author: Saad Haj Bakry, King Saud University, Riyadh, Saudi Arabia, Tel: +966 11467 0000; E-mail: shb@ksu.edu.sa.

Receved February 18, 2015; Accepted February 28, 2015; Published March 10, 2015

Citation: Muhaya FB, Bakry SH, AlAlmaee SM (2015) E-Government Success Factors: Views of Saudi Professionals. J Entrepren Organiz Manag 4: 128. doi: 10.4172/2169-026X.1000128

Copyright: (c) 2015 Muhaya FB, et al. This is an open-access article distributed under the terms of the Creative Commons Attribution License, which permits unrestricted use, distribution, and reproduction in any medium, provided the original author and source are credited. 
e-government, e-governance can be defined as the use of ICTs as a tool to achieve better governance.

\section{Development of e-government}

Development of e-government has been receiving support at different level; and here are some examples:

$>$ At the international level, support has come through the following:

o The Millennium Development Goals (MDG) issued by world leaders after their United Nations (UN) meeting in the year 2000, at the turn to the third millennium [4].

o The World Summit on Information Society held in Geneva in 2003 and subsequently in Tunis in 2005 [5].

o The United Nations Department of Economic and Social Affairs (UNDESA), which publishes an annual worldwide survey of e-government development [6].

$>$ At the national level, various governments have produced plans and initiated e-government development programs, like the various national plans $[7,8]$ and "YESSER" e-government program [9] in Saudi Arabia.

$>$ At the sector level, various sectors have been developing their own e-services such as the government health sector of Saudi Arabia [10].

$>$ At the researchers' level, a group at King Saud University has produced a framework for the development of e-government [3], and this has been highly sighted and used [11]. In addition, YESSER researchers have published a planning initiative for e-government services at a specialized international conference in Ireland [12]. It should be noted that the development of e-government is not a startstop process, but it is a cyclic continuous process that requires continues response to accumulated experience, advancement of technology, changing demands, and other dynamic issues.

\section{This Paper}

This paper is concerned with the assessment of e-government success factors using the experience of those who have been involved in e-government development and management in Saudi Arabia since 2005 when "YESSER" program was initiated. For this purpose, the paper presents a multi-level framework that incorporates basic e-government success factors. It provides a survey questionnaire that enables the e-government professionals to assess the importance and current state or impact of these factors. The outcome of the work would be useful in supporting the future development of e-government toward enhanced success.

\section{Success Factors: A Multi-Level Framework}

The levels of the framework of the basic e-government success factors considered here are illustrated in Figure 2. This section presents these factors according to each level; and it also shows how the assessment of these factors has been enabled through a survey questionnaire.

\section{The international level}

This level is concerned with factors related to international influence; they involve the following:

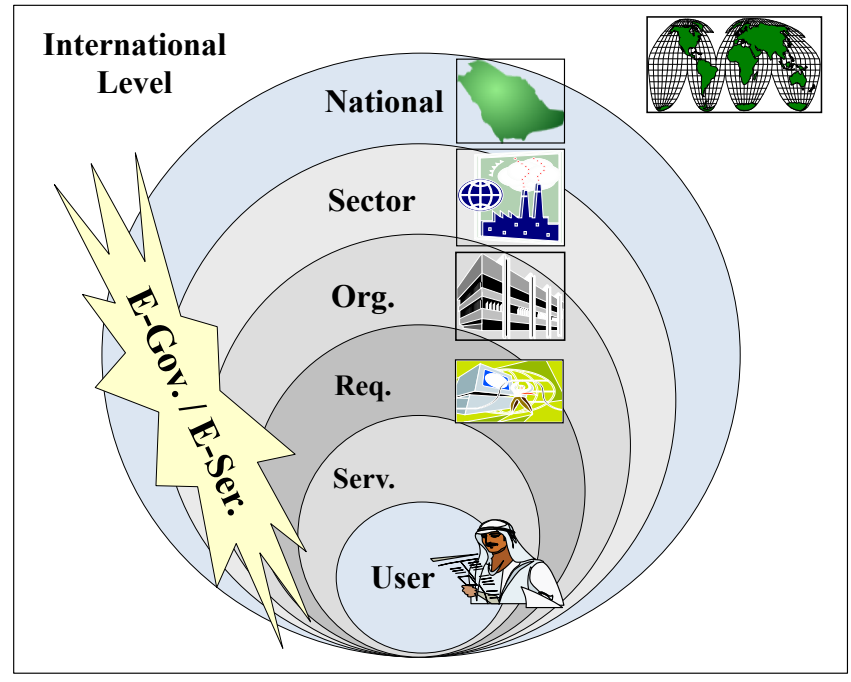

Figure 2: The levels of the framework incorporating the basic e-government success factors considered.

- The MDG direction toward supporting the utilization of ICT for development [4].

The WSIS direction toward enhancing ICT services and expanding their use [5].

- The UNDESA annual assessment and ranking of the e-government state in different countries [6].

- The existent of international cooperation or an international center for sharing knowledge, skills, and experience at the world level, with respect to e-government implementation.

- The presence of international technical and management standards for the various issues of e-government implementation.

\section{The national level}

This level is related to factors concerned with national influence; and they include the following.

T The direction of the Saudi national science and technology policy toward ICT development and use [7].

The direction of the Saudi national ICT policy toward enhanced and expanded ICT services [8].

口 The direction of "YESSER" program toward supported e-government development all over Saudi Arabia.

- The existent of national cooperation or a national center for sharing knowledge, skills, and experience, with respect to Saudi e-government implementation.

- The presence of Saudi national technical and management standards for the various issues of e-government implementation.

\section{The sector level}

In e-government, various sectors have their own special issues, in addition to the general issues. This level is related to factors concerned with sector specific issues; and these include the following.

口 Sector directions toward e-government and e-services development. 
D Directions of professional societies associated with the sector.

The actual sector plans and projects.

- The existent of sector-level cooperation or special sector center for sharing knowledge, skills, and experience for enhanced implementation.

- The presence of sector technical and management standards.

\section{The organization level}

This level is concerned with factors associated with individual organizations issues; and these include the following.

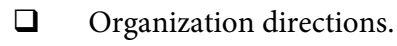

․ Top management attitude.

- Actual plans and projects.

- The existent of clearly identified implementation responsibilities.

- The presence of organization's technical and management standards.

\section{The requirements level}

This level is concerned with factors associated with e-government requirements issues; and these include the level of readiness of the following issues.
- Financial resources.
口 Human resources.
ICT infrastructure.
E E-government technical requirements.
Information security.

\section{The services level}

This level is concerned with factors associated with delivering e-government services; and these include the level of availability of the following.

D Download of needed information.

Exchange of information.

口 Delivery of simple direct services.

口 Delivery of sophisticated services that involve multi-party interaction.

D Delivery of smart services, such as those of grid computing [13].

\section{The user level}

This level is concerned with factors associated with the e-government user; and these include the following.

- User awareness and skills in using the e-government services.

ㄴ User drive toward using the services.

The existent of cooperation or user groups to promote making use of the services.

T The existent of help, feedback and cooperation channels between users on the one hand and those at the levels above on the other.

U User behavior in making use of the services.

\section{Assessment issues}

The above proposed "35 e-government success factors" have been incorporated in a questionnaire, according to their levels, for the purpose of enabling Saudi e-government professionals to give their views of each one of them. Two issues are considered for each factor: its importance; and its current state or impact. Each issue is assessed according to the six grades given in Table 1.

\section{Assessment of Success Factors: A Survey}

The questionnaire of the framework has been presented and distributed in a "YESSER" meeting attended by Saudi professionals responsible for e-government services in Saudi Arabia. The questionnaire was answered by " 88 professionals"; and the results obtained are presented in the following.

\section{The international factors}

Figure 3 presents the collective outcome of grading for each international success factor considering: its importance, and its current state or impact. The results obtained illustrate the following:

- The grades concerned with the importance of the international factors range from average to above average, and do not go beyond above average except for international standards.

- The grades of the impact or current state of these factors range from below average to average, which is clearly much lower than the grade for the importance.

- The relative differences in grades between importance and impact or current state range from " $50 \%$ " for MDG to around " $70 \%$ " for cooperation.

\section{The national factors}

Figure 4 presents the collective outcome of grading for each national success factor including: its importance, and its current state or impact. The results obtained indicate the following:

\begin{tabular}{|c|c|c|c|c|c|}
\hline 0 & 1 & 2 & 3 & 4 & 5 \\
\hline Non-existent & Low & $\begin{array}{c}\text { Below } \\
\text { Average }\end{array}$ & Average & $\begin{array}{c}\text { Above } \\
\text { Average }\end{array}$ & High \\
\hline
\end{tabular}

Table 1: The grades of assessing the success factors used for both: factor importance and its current state or impact.

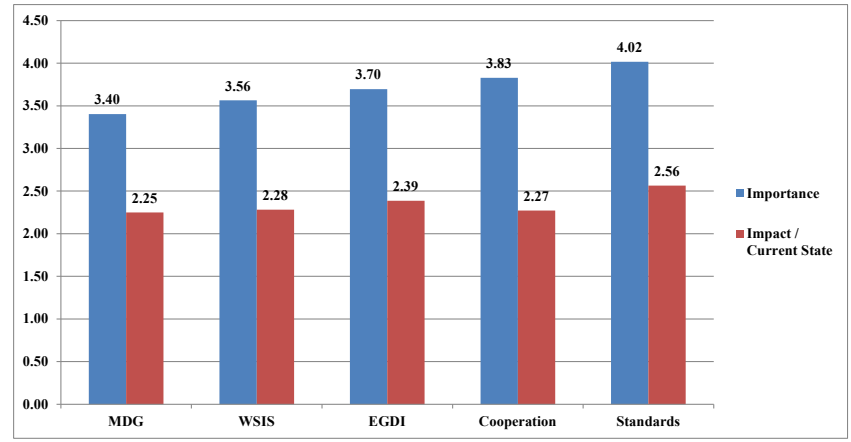

Figure 3: Expert grading of international success factors. 


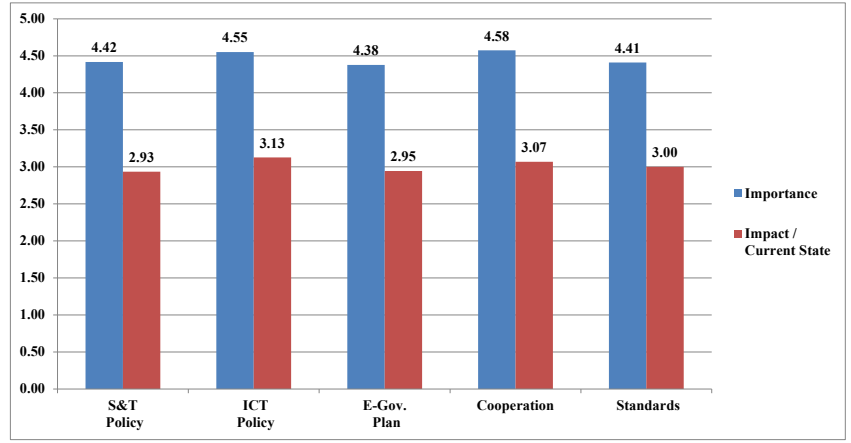

Figure 4: Expert grading of national success factors.

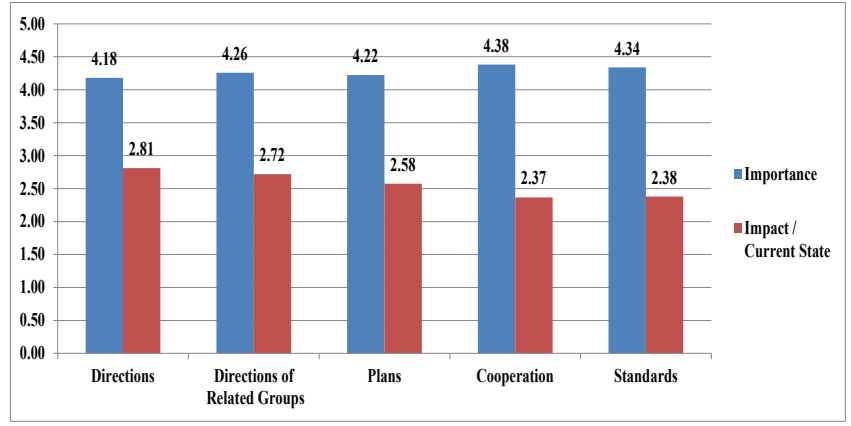

Figure 5: Expert grading of sector success factors.

- The grades concerned with the importance of the national factors are well advanced with all exceeding the grade of above average toward the high grade.

The grades of the impact or current state of these factors are around average.

- The relative differences in grades between the importance of the national factors and their impact or current state range from around " $45 \%$ " for the national ICT policy to over " $50 \%$ " for the national science and technology.

\section{Assessment of sector factors}

Figure 5 shows the collective outcome of grading for each sector level factor including: its importance, and its current state or impact. The results obtained illustrate the following:

Like the national factors, the grades concerned with the importance of the sector factors are well advanced with all exceeding the grade of above average.

The grades of the impact or current state of these factors do not reach the grade of average.

The relative differences in grades between the importance of the sector factors and their impact or current state range from around " $50 \%$ " for sector directions to over " $80 \%$ " for cooperation.

\section{Assessment of organization factors}

Figure 6 shows the collective outcome of grading for each organization level factor including: its importance, and its current state or impact. The results obtained illustrate the following:
L Like the above two levels, the grades concerned with the importance of the organization factors are well advanced with all exceeding the grade of above average.

- The grades of the impact or current state of these factors range from below average to around average.

- The relative differences in grades between the importance of the national factors and their impact or current state range from around " $45 \%$ " for the organization directions, management and plan to over "70\%" for responsibility.

\section{Assessment of requirements factors}

Figure 7 shows the collective outcome of grading for each requirements level factor including: its importance, and its current state or impact. The results obtained illustrate the following:

- Like the above three levels, the grades concerned with the importance of the requirements factors are well advanced with all well exceeding the grade of above average.

The grades of the impact or current state of these factors range from below average to around average.

- The relative differences in grades between the importance of the national factors and their impact or current state range from around " $50 \%$ " for the financial resources to over " $70 \%$ " for human resources.

\section{Assessment of services factors}

Figure 8 shows the collective outcome of grading for each services

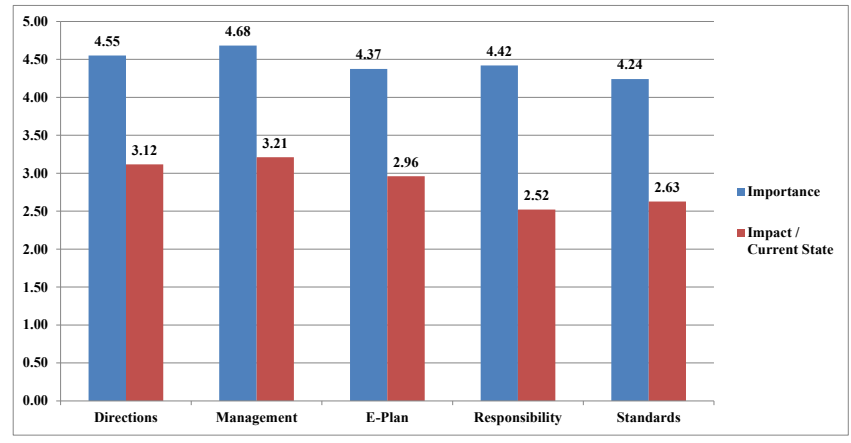

Figure 6: Expert grading of organization success factors

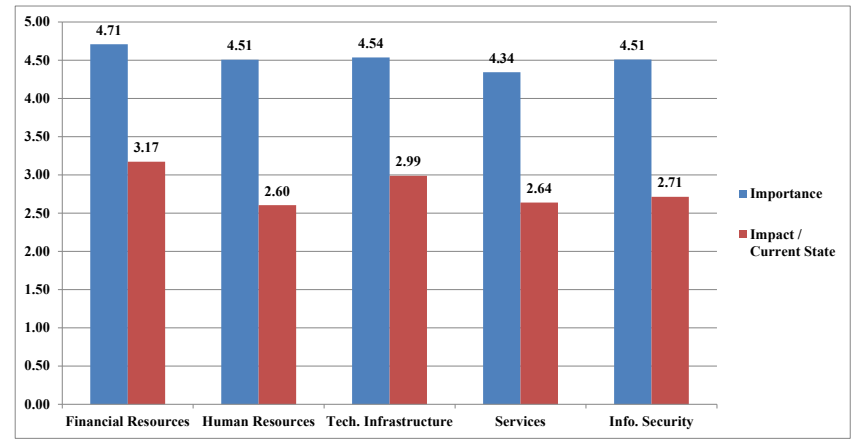

Figure 7: Expert grading of requirements success factors. 


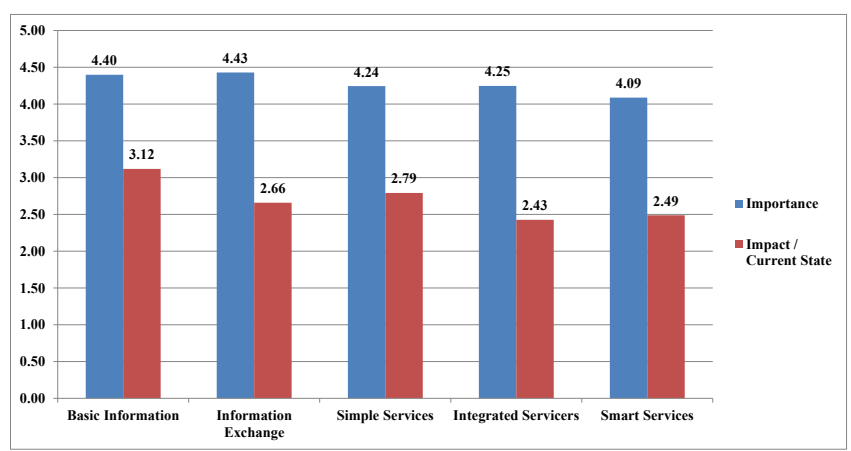

Figure 8: Expert grading of services success factors.

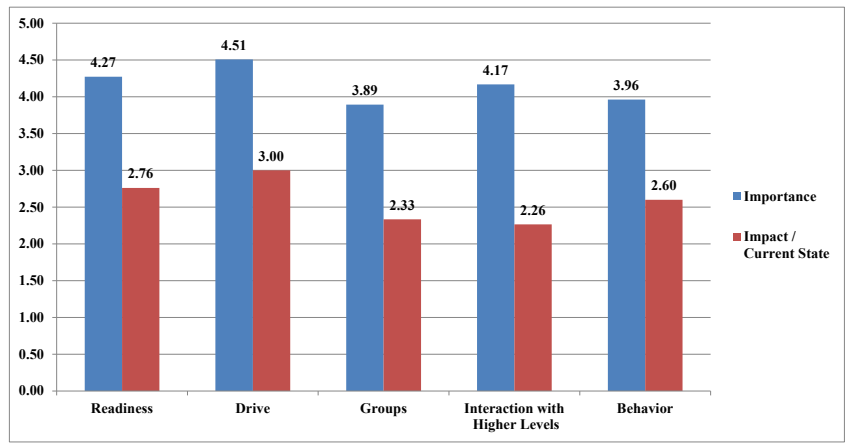

Figure 9:Expert grading of user success factors.

level factor including: its importance, and its current state or impact. The results obtained illustrate the following:

Like the above four levels, the grades concerned with the importance of the services factors are well advanced with all exceeding the grade of above average.

The grades of the impact or current state of these factors range from below average to around average.

The relative differences in grades between the importance of the services factors and their impact or current state range from around " $40 \%$ " for basic information delivery to over " $70 \%$ " for integrated services.

\section{Assessment of user factors}

Figure 9 shows the collective outcome of grading for each user level success factor including: its importance, and its current state or impact. The results obtained illustrate the following:

Three out of five grades concerned with the importance of the services factors are exceeding the grade of above average, while the rest are slightly less.

The grades of the impact or current state of these factors range from below average to around average.

The relative differences in grades between the importance of the services factors and their impact or current state range from around " $50 \%$ " for user drive to over " $80 \%$ " for user interaction with higher levels.

\section{Conclusions and Future Work}

The work presented in this paper is one example of a knowledge sharing exercise concerned with e-government success factors among Saudi professionals in charge of e-government services. Such exercises would support e-government success through views and feedbacks that promote future development with collective wisdom. While the work explores " 35 potential success factors", other factors may be explored in other knowledge sharing exercises in the future. In addition, future knowledge sharing exercises may be extended to include not only e-government professionals, but also e-government users. This would provide a richer knowledge base and enhanced collective wisdom for the future development of e-government services.

Within the scope of the work presented in this paper, the collective views on the importance of " 29 " factors exceeded the grade of above average toward the high grade; while " 6 " factors did not reach above average, but exceeded average on the scale considered. "4" out of these " 6 " factors are associated with the international level, while the other " 2 " are related to the user level.

The gap between the importance and the impact or current state for all " 35 " factors was quite wide. It reached no less than " $40 \%$ " and went up to over " 80 " percent. This leads to the conclusion that future e-government plans should consider the promotion of the current state and impact of all " 35 " factors considered. Ways for doing so, would involve various development issues that need to be studied including: human, technical, and management issues, which are of dynamic nature.

In summary, future integrated action is recommended for Saudi Arabia and other countries on the following main issues:

- The development of a program of knowledge sharing exercises for the continuous assessment and improvement of e-government. Such exercises should not only involve e-government professionals but also users.

The initiation of research work concerned with finding better human, technical and management ways for enhancing the impact of the important success factors on e-government development.

- Building a dynamic knowledge base that considers the continuous changes of e-government technology, management practices, innovative applications, demands and other dynamic issues.

- These integrated work dimensions would provide useful tools for the future development of e-government for the benefit of building an efficient and effective knowledge-based society.

\section{Acknowledgement}

The authors acknowledge the support of QIYAS Project of Saudi E-Government Program (YESSER)-and-King Abdullah Institute for Research and Consulting Studies of King Saud University. They wish also to thank the Saudi e-government professionals who shared their views on e-government success factors.

\section{References}

1. Aldeen JR, Bakry SH, Nouh A (2000) Performance-based evaluations of the tangible benefits of information networks with applications. International Journal of Network Management 10: 91-101.

2. Bakry SH, Muhaya F (2011) Assessing the benefits of e-government. Second Kuwait Conference on e-Services and E-Systems, Kuwait.

3. Bakry SH (2004) Development of e-government: a STOPE view. International Journal of Network Management 14: 339-350.

4. ITU (2003) World Telecommunication Development Report: Access Indicators 
Citation: Muhaya FB, Bakry SH, AIAlmaee SM (2015) E-Government Success Factors: Views of Saudi Professionals. J Entrepren Organiz Manag 4: 128. doi:10.4172/2169-026X.1000128

Page 6 of 6

for the Information Society. International Telecommunication Union, Switzerland.

5. WSIS (2003) Declaration of Principles: Building the Information Society: a global challenge in the new Millennium. World Summit on the Information Society (WSIS), Geneva 2003-Tunis 2005.

6. United Nations Department of Economic and Social Affairs (UNDESA) (2014) UN E-Government Survey.

7. STNP (2013) Science and Technology National Policy, King Abdulaziz City for Science and Technology.

8. NCITP (2013) National Communication and Information Technology Plan, Saudi Ministry of Communication and Information Technology.
9. YESSER (2003) E-Government Program, Saudi Ministry of Communication and Information Technology.

10. NEHS (2013) National E-Health Strategy, Saudi Ministry of Health.

11. Esteve J, Joseph RC (2008) comprehensive framework for the assessment of e-Government projects, Government Information Quarterly 25: 118-132.

12. Al-Almaee SM, Khayyat WR (2010) Strategic planning and supporting initiatives department: Saudi e-government program. 10 $10^{\text {th }}$ European Conference on e-Government, National Centre for Taxation Studies, University of Limerick, Ireland.

13. Arafah MA, Al-Harbi H, Bakry SH (2007) Grid computing: a STOPE view. International Journal of Network Management 17: 295-305. 